\title{
CORRECTION
}

\section{Correction to: Sustainable biocomposites produced from cotton stalk wastes: Effect of heat treatment}

\author{
Shiyan $\mathrm{Gu}^{1} \cdot$ Lanlan Chang $^{1} \cdot$ Qingfa Zhang ${ }^{2} \cdot{\text { Hongzhen } \mathrm{Cai}^{3} \cdot \text { Ruji Wang }^{1} \cdot \text { Jiyang Sun }}^{1}$ \\ Published online: 28 February 2022 \\ ๑) The Polymer Society, Taipei 2022
}

Correction to: Journal of Polymer Research (2022) 29:42

https://doi.org/10.1007/s10965-021-02878-3

The 2nd author Lanlan Chang's affiliations was mistakenly captured and the title of Fig. 10 is wrong.

The corrected 2nd author's affiliation and Fig. 10 caption are shown below:

1 School of Engineering, Shenyang Agricultural University, Shenyang 110866, China

"Fig. 10 Dimensional stability of composites samples".

The original article has been corrected.

Publisher's Note Springer Nature remains neutral with regard to jurisdictional claims in published maps and institutional affiliations.

The original article can be found online at https://doi.org/10.1007/ s10965-021-02878-3.

Shiyan Gu

gushiyan@syau.edu.cn

Qingfa Zhang

zhangqingfa@zju.edu.cn

1 School of Engineering, Shenyang Agricultural University, Shenyang 110866, China

2 College of Biosystems Engineering and Food Science, Zhejiang University, Hangzhou 310058, China

3 School of Agricultural Engineering and Food Science, Shandong Research Center of Engineering \& Technology for Clean Energy, Shandong University of Technology, Zibo 255000, China 